\title{
Small renal carcinoma: the "when" and "how" of operation, active surveillance, and ablation
}

\author{
Jakob Johann Wendler ${ }^{1 A, B, D, E, F}$, Bernd Uwe Liehr ${ }^{10, E}$, Robert Damm ${ }^{2 B, D, E}$, Maciej Powerski ${ }^{20, E}$, Thomas Brunner ${ }^{3 E, F}$, \\ Martin Schostak ${ }^{1 D}$, Maciej Pech ${ }^{2 A, B, D, E, F}$ \\ 'University Clinic for Urology, University of Magdeburg, Germany \\ ¿University Clinic for Radiology, University of Magdeburg, Germany \\ ${ }^{3}$ University Clinic for Radiotherapy, University of Magdeburg, Germany
}

\section{Abstract}

Small, locally restricted renal cell carcinoma less than $4 \mathrm{~cm}$ in size should ideally be removed operatively by nephron-sparing tumour enucleation (partial kidney resection). In an increasingly elderly population, there is a growing trend toward parallel incidence of renal cell carcinoma and chronic renal insufficiency, with the latter's associated general comorbidities. Thus, for some patients, the risks of the anaesthesia and operation increase, while the advantage in terms of survival decreases. Transcutaneous radio-frequency ablation under local anaesthesia, transcutaneous afterloading high-dose-rate brachytherapy under local anaesthesia, and percutaneous stereotactic ablative radiotherapy may offer a less invasive alternative therapy. Active surveillance is to be regarded as no more than a controlled bridging up to definitive treatment (operation or ablation), while watchful waiting, on account of the lack of prognostic relevance and the symptomatology of renal cell carcinoma, with its comorbidity-related, clearly reduced life expectancy, does not involve any further diagnostic or therapeutic measures.

Key words: renal cell carcinoma, small renal tumour, active surveillance, ablation, focal therapy.

\section{Introduction}

Renal cell carcinoma (RCC) is one of the 10 most common malignomas. Its increasing incidence results from increased age, morbidity, and noxa, as well as from the increasingly widespread use of modern imaging techniques [1]. In parallel, there is an increasing frequency of comorbidities (with negative influence upon oncological disease progression) and chronic renal insufficiency (associated a priori with poorer life expectancy). Early-stage RCC is usually discovered by chance [2]. This epidemiological development and the possible side effects of immediate renal tumour resection call for alternative therapies.

\section{"Small" renal tumour}

RCC in early stages is usually asymptomatic and is therefore usually discovered by chance, in screening or in the diagnosis of other disorders. Empirically, any solid growth on the kidney must arouse suspicion of RCC. If imaging reveals typical criteria for suspicion of malignant growth, then the presence of RCC must be suspected. According to current guidelines, this would comprise a sufficient indication for surgical removal of the tumour, without prior confirmation by biopsy and histology, as long as there are no contra-indications for operation by intubation narcosis $[1,2]$.

The term "small renal tumour" is primarily an image-based morphological description of a solid growth

Correspondence address:

Dr. Jakob Johann Wendler, Universitätsklinik für Urologie u. Kinderurologie, Universitätsmedizin Magdeburg (UMMD) A.ö.R., 44 Leipziger Str.,

39120 Magdeburg, Germany, e-mail: Johann.wendler@med.ovgu.de

Authors' contribution:

A Study design · B Data collection · C Statistical analysis · D Data interpretation - E Manuscript preparation · F Literature search · G Funds collection 
on the cortical renal parenchyma, without any assessment of the nature, malignity, or exact location. In English-speaking countries this is termed "small renal mass" (SRM) when its diameter is $3 \mathrm{~cm}$ or less [3]. In continental Europe, a solid growth in the renal parenchyma extending up to $4 \mathrm{~cm}$ is referred to as a "small renal tumour" (German kleiner Nierentumor); this is analogous to the T category "cT1a, cN0, cM0; stage 1" in the 2017 UICC (Union Internationale Contre le Cancer) classification for locally restricted non-metastasised RCC [1-5]. The prognostic limit of $4 \mathrm{~cm}$ for $\mathrm{T} 1 \mathrm{a}$ is of historical origin and does not agree with recent results according to which the rates of growth and metastasis increase exponentially above a tumour size of $3 \mathrm{~cm}$. Experience has been gathered in clinical studies up to a tumour size of $3 \mathrm{~cm} \mathrm{[2].}$

Numerous studies of the progress of T1a small renal tumours have shown a relatively slow annual growth, with a very low rate of metastasis in the first five years, but it must be noted that these results include a significant number of uncertainly diagnosed or benign tumours and various RCC subtypes [6,7]. Up to 20-30\% of SRMs turn out in histological analysis to be benign oncocytomas [8]. Chawla et al. performed a meta-analysis for the subgroup of biopsy-confirmed pT1a RCCs $(n=120)$ with a median tumour size of $2.48 \mathrm{~cm}$ (range $1.7-4.0 \mathrm{~cm}$ ); they found a median annual growth rate of $0.35 \mathrm{~cm}$ (range $0.42-1.6 \mathrm{~cm}$ ) in an average observation period of 30 (range 25-39) months [9]. Jewett et al. analysed 101 biopsy-confirmed pT1a RCCs, finding a progression rate of $0.13 \mathrm{~cm} /$ year and a metastasis rate of $1.1 \%$ per year in a median observation period of 28 months [10]. Thompson et al. reported a metastasis rate of $0.0013 \%$ (1/720) for RCC smaller than $3 \mathrm{~cm}$ in a median observation period of 2.8 years. They found an increase in metastasis rate of $24 \%$ for each $1 \mathrm{~cm}$ tumour size increase [11]. Thus, tumour size is one of the most important prognosis factors for the course of disease and for metastasis.

In early stages the localised RCC mainly displaces other tissue and to some extent permeates it. Often, a peritumoral pseudocapsule ("surgical capsule") arises through compression of healthy cells in the surrounding tissue and of peripheral tumour cells [7]. This pseudocapsule, on average only $0.5 \mathrm{~mm}$ thick, is individually formed and can

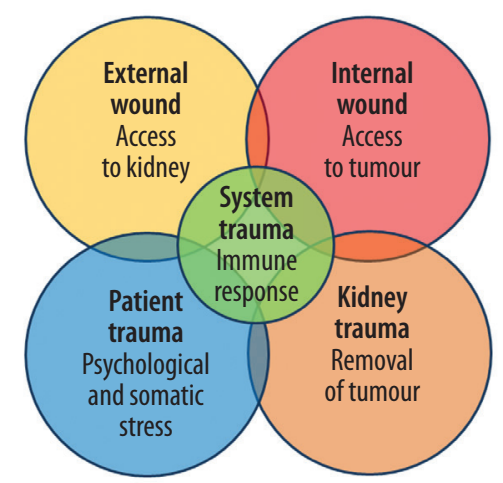

Figure 1. Procedures and their respective degrees of invasiveness, to be considered in the choice of therapy vary from a complete or incomplete pseudocapsule with or without tumour infiltration through to a completely absent pseudocapsule [12,13]. Sometimes microscopic satellite tumours are found in the immediate vicinity of the macroscopic tumour [14].

\section{Biopsy}

Confirmation of a renal tumour by biopsy and histological analysis, prior to possible surgical treatment, is not routinely recommended, because it does not affect the choice of treatment and also because of residual diagnostic uncertainty. According to the S3 guidelines, biopsy should be performed in cases of unclear solid growths on the kidney when this might affect the choice of therapy, when active surveillance (AS) is being considered, or when ablation is due to be performed [1]. For solid tumours a double coaxial cylinder biopsy for histological analysis (18G needle), outside any region of possible central tumour necrosis, is recommended. Despite the relatively high sensitivity and specificity of the biopsy-based test for a solid RCC, there is still a high rate (up to 20\%) of false negatives or uninformative samples. In a meta-analysis of 1330 small (2.4-4.1 cm diameter) renal tumour biopsies, directed by coaxial computed tomography, the accuracy of targeting was $78-100 \%$ and the correct assignment of malignity was $86-100 \%$; whereby the accuracy was $86-100 \%$ for the histological RCC subtype and $46-76 \%$ for the gradings [15]. A negative biopsy (finding of normal parenchyma) should therefore be followed by a repeat biopsy if this is required for support of the choice of therapy. A further limitation of diagnosis by biopsy to determine the exact tumour entity is the intratumoural biological heterogeneity of the RCC, although this can be less clearly visible for smaller tumours [16]. Oncocytomas, which are fundamentally classified as benign, are in some cases difficult to distinguish from oncocytically differentiated RCC; sometimes this can only be done by histochemistry, and it appears possible that such tumours can degenerate to carcinomas [17].

\section{The "inoperable" patient}

From a purely surgical, technical standpoint, every locally restricted kidney tumour and every patient affected is in principle operable. A general, or functional inoperability arises through severe comorbidity that renders impossible either the intubation anaesthesia with muscle relaxants or the necessary peri-operative management, or that makes the immediate or subsequent risk for the patient unjustifiably high. Therefore, for every patient, one must perform a critical risk-benefit analysis of any curative treatment, be it by tumour resection or by interventional ablation. This consideration must take account of the degree of invasiveness - individually and overall - of the various measures to be taken (Figure 1). 
The term "minimally invasive" for invasive procedures is frequently narrowed to refer only to the external access (external wound). However, in the case of kidney tumour, the internal access to the tumour itself and the damage inflicted collaterally on the renal parenchyma have a major influence upon the risk of perioperative complications and the patient's subsequent quality of life. Here the patient's age and general condition are particularly important for the prognosis. The incidence of renal tumour peaks in the seventh decade, so most of those affected are elderly ('younger old', 65-74 years; 'mid-old', 75-84 years; 'old-old', $\geq 85$ years; definitions by the International Society of Geriatric Oncology [SIOG] $[18,19])$. A structured geriatric assessment (Barthel Index, Mini-Mental-State Test, Tinetti Test) and a systematic recording of comorbidities (Charlson Comorbidity Index, American Society of Anaesthesiologists [ASA] Score, degree of sarcopaenia, Eastern Cooperative Oncology Group [ECOG] status) allow individual decision-making, and in about half of all cases they lead to a change in therapy decision [20-24] by consideration of the patient's mobility, competence in everyday situations, resilience, and life expectancy.

Hand in hand with the patient's age and morbidity, there is an increasing risk of peri- and post-operative complications and, moreover, a risk of death due to comorbidities. Thus, the complication rate in partial renal resection among patients under 50 years of age is around $30 \%$ and among 80 -year-olds it is around 50\%. In the presence of relevant comorbidities (Charlson in$\operatorname{dex} \geq 2$ ) the complication rate in partial renal resection and tumour nephrectomy is six times higher than in their absence [25]. Among the over-80s severe interventionrelated complications occur in 35\% of cases (Clavien-Dindo $\geq$ III), with a mortality of around 3\% [26]. Lane et al. investigated 537 patients with SRM; for those aged $\geq 75$ years he found no significant difference in survival between AS and surgical treatment (partial renal resection and tumour nephrectomy). In that survey $28 \%(n=148)$ of the patients died within the median follow-up period of ca. four years, whereby $24 \%$ of the deaths had causes other than progressive, metastasising RCC; most were due to cardiovascular disorders [27]. Likewise, Sun et al. found no survival advantage of resecting small RCCs as regards carcinoma-specific mortality among patients aged over 75 years or among those with a Charlson Comorbidity Index of 2 or above [28,29].

The degree of collateral damage to healthy peritumoral renal parenchyma caused by invasive treatment is correlated with the risk of chronic renal insufficiency or its worsening and with the associated cardiovascular comorbidity, with consequent reductions in the patient's life expectancy and quality [30,31]. The development of kidney-preserving, nephron-sparing therapies is therefore an important goal. If renal tumour enucleation, enucleoresection, and sparing partial renal resection all appear unpromising and nephrectomy is considered highly risky, then for patients with chronic renal insufficiency, with only one kidney or with metachronic, multilocular RCC growth patterns (imperative indication for kidney preservation) ablative treatment should be considered as an alternative to resection (Figure 2).

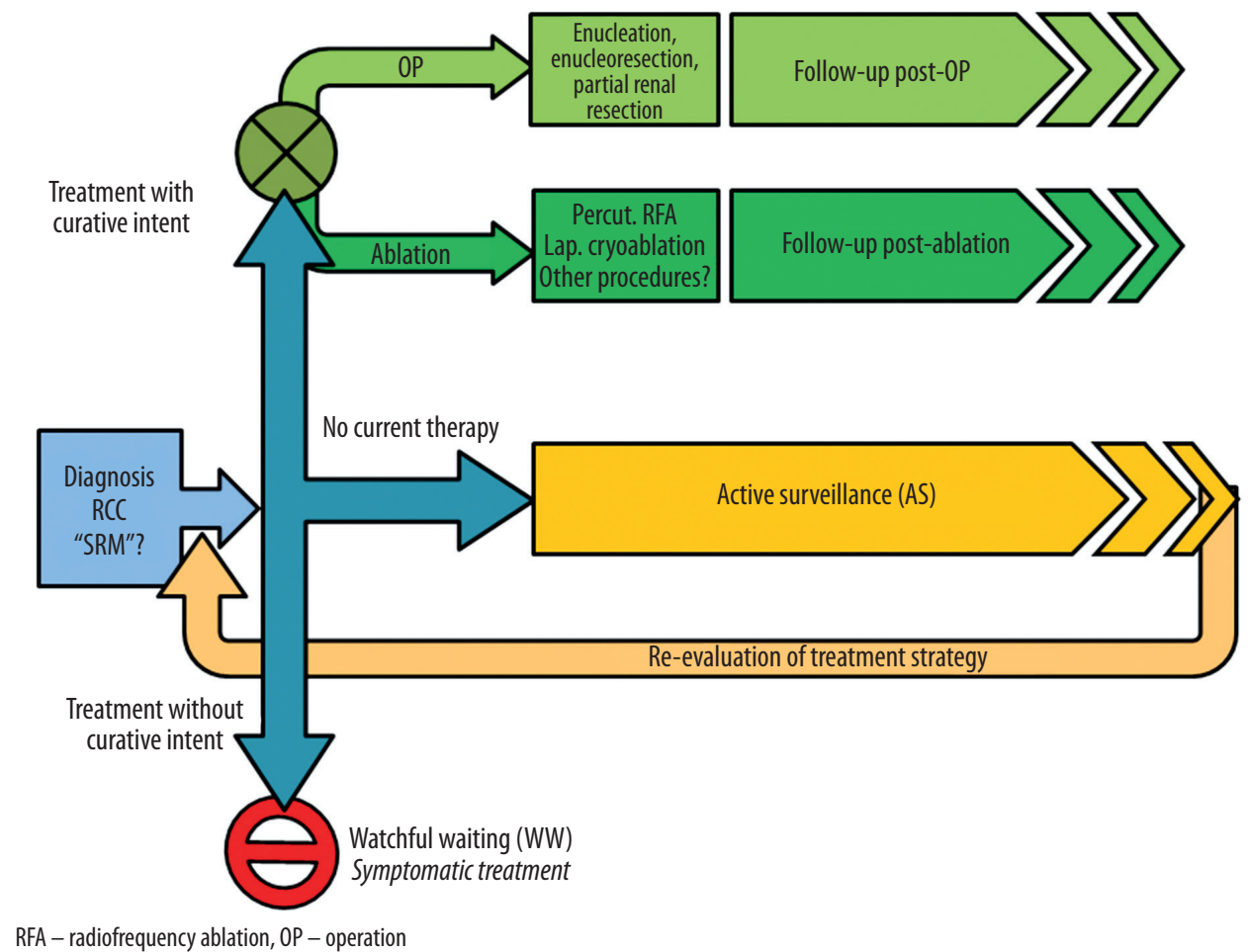

Figure 2. Decision algorithm for treating small renal mass (SRM) or renal-cell carcinoma (RCC) 
Damage to healthy renal parenchyma caused by invasive treatment is correlated with the risk of chronic renal insufficiency. Decisive factors for the success and for the complication rate are also the position and the size of the renal tumour. Anatomical classification systems, such as the PADUA (preoperative aspects and dimensions used for anatomical classification) score, the R.E.N.A.L. (radius, exophytic/endophytic, nearness to collecting systems or sinus, anterior/posterior, and location relative to polar lines) score, the CIndex, and the ABLATE algorithm, are intended to be used as aids to decide the type of treatment (operation and operative method; ablation and ablation method; AS) [32,33].

For patients with a reduced life expectancy - on the basis, e.g., of advanced age or very severe comorbidity - following the course of an asymptomatic tumour (discovered by chance) would mean psychological and physical stress; this would be unnecessary and would have no therapeutic value. For patients of this kind, a strategy of waiting, without directed diagnoses or therapy, should be considered. This "watchful waiting" or "wait-and-see" procedure differs fundamentally, in indication and in conduct, from AS (Figure 2).

\section{Active surveillance}

If postponement of invasive treatment of locally restricted RCC (resection or ablation) is indicated or is desired by the patient, then AS is the first option. By definition, AS is indicated if any of the following apply:

- Immediate invasive therapy is currently medically contra-indicated because of temporarily elevated risks (such as recent myocardial infarction, need for multiple anticoagulant treatment, etc.) or other recent or current treatments (such as convalescence from another operation, incomplete diagnosis of another prognostically relevant disorder, etc.).

- The patient wishes, for personal or social reasons, to postpone curatively intended therapy (family or professional situation, holiday planning, etc.).

- The malignity is unclear, owing to ambiguous diagnosis, and/or the patient is afraid of side effects or complications of the treatment that might have a permanent impact upon their quality of life. In either case the patient may choose to postpone therapy and wait until there is local progression, with invasive treatment more urgently indicated (assuming that no contra-indication has arisen in the meantime). In this way the patient avoids "over-treatment".

Such decisions are reached on an individual basis, if necessary with interdisciplinary and multicentric support. Nonetheless, there remains a residual uncertainty - with both patient and physicians - as to whether the patient is after all being under-treated. There always remains a possibility that the disease will worsen during AS toward an incurable state or a more complicated treatment status - because of local disease progression, metastasis, or some other, additional disorder than might influence the patient's prognosis. This perpetual unease about the possibility of under-treatment, or excessive postponement of treatment, will in itself cause a relevant reduction in quality of life, and for this reason a large proportion of patients decide a priori against AS or abandon AS in favour of a definite therapy [16].

The idea of AS arose at a time when there was a lack of therapeutic alternatives to operation and, consequently, a danger of surgical over-treatment with the associated risk of substantial adverse side effects and complications, as well as increased costs for the health-care system. The theoretical basis for AS is the above-mentioned low rate of growth and metastasis for RCCs less than $3 \mathrm{~cm}$ in size. Strictly speaking, AS at first only comprises regular imaging for the purpose of restaging. It should only be offered for RCC with a low risk of progression and metastasis, after needle biopsy and histological confirmation of the tumour. Generally, AS is not recommended for renal tumours that are larger than $3 \mathrm{~cm}$, are not sharply defined, are clearly inhomogeneous, or are found by biopsy and histology to be high-grade RCC; it is also not recommended for patients who are young and otherwise healthy. However, there is no recommended scheme setting out the type or interval of imaging. Imaging within AS should be performed at least once a year. The concept of rebiopsy within the course observation of renal tumours during AS is likewise not established. For this reason, AS is generally only conducted with check-ups by imaging. For AS of SRM and pT1a RCC there exist data from retrospective studies and metaanalyses, but there is no information from prospective, randomised studies. The increasing established possibility of ablation reduces the scope of indication for AS.

\section{Local ablation procedures}

Percutaneous ablation techniques performed under local anaesthesia are increasingly filling the gap between operative and conservative treatment. With the increasing availability of appropriate guidelines, at present more than $10 \%$ of small renal tumours are treated by ablation $[1-3,34,35]$. This raises a need to compare the various ablation techniques with one another, and with the various operative methods, in respect of invasiveness, quality of life, complication rate, success rate (tumour control), and post-interventional preservation of renal function. Currently there are a lack of randomised, controlled studies on this subject.

The best surgical method for preserving renal parenchyma is enucleation of the kidney tumour (Figure 3C) without ischaemia and without profound local haemostasis (the "surgical ideal"). In enucleoresection of kidney tumour (Figure $3 \mathrm{~B}$ ) and partial renal resection (Figure 3A) a variable amount of the healthy peritumoral parenchyma 
A

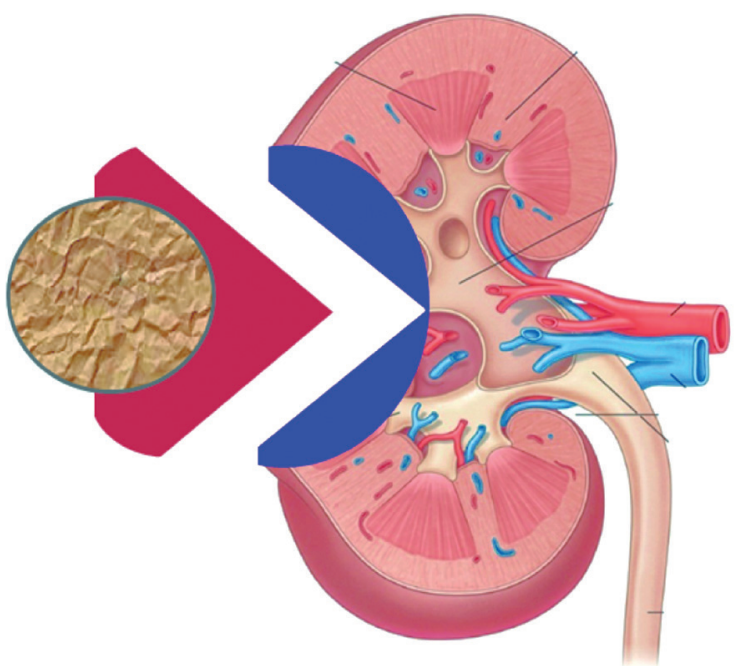

B

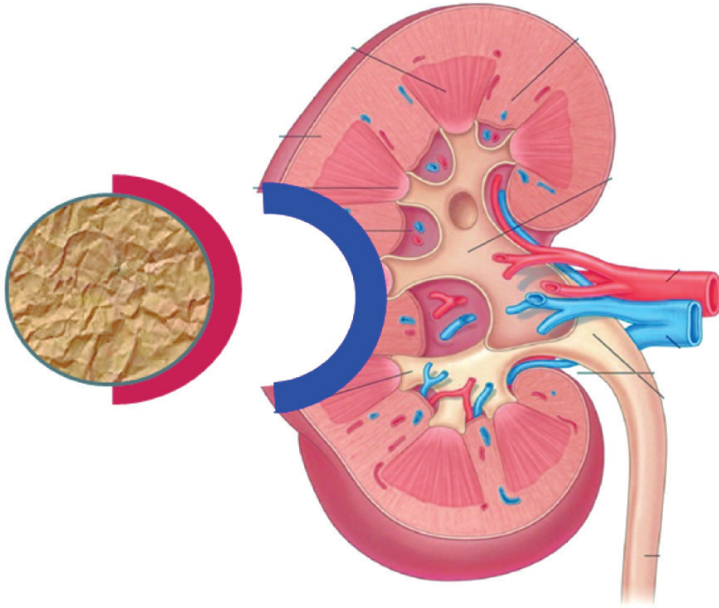

C
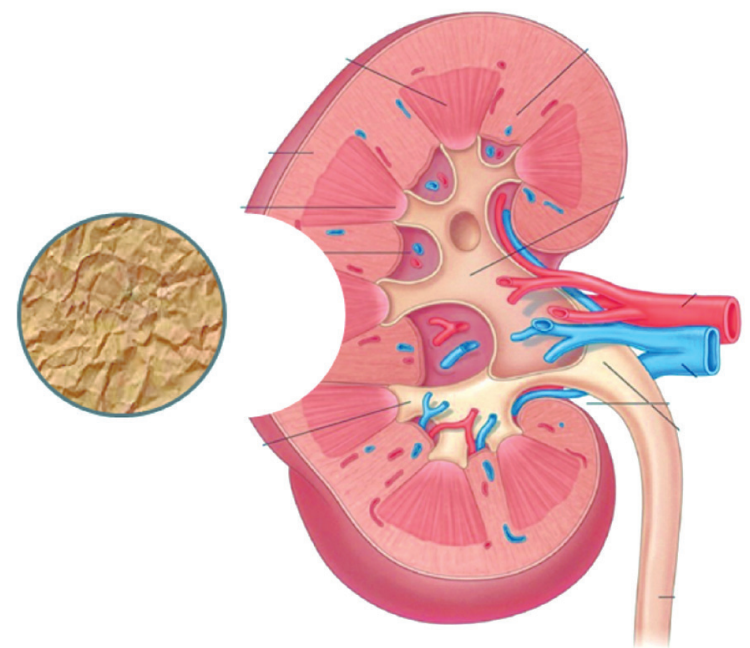

Figure 3. Operative techniques for removal of renal tumour (red, coresected healthy peritumoral parenchyma; blue, healthy parenchyma subjected to secondary damage by haemostatic and adaptive blood supply to the peripheral resected region). A) Partial renal resection, B) enucleoresection, C) enucleation ("ideal")

is coresected, and, as a rule, extended supply to the resection bed is performed, often with ischaemia (Figure 3). This should be contrasted with all non-surgical ablation methods; there, as a rule, the (technically inevitable) centrifugal effect gradient and the intra-interventional
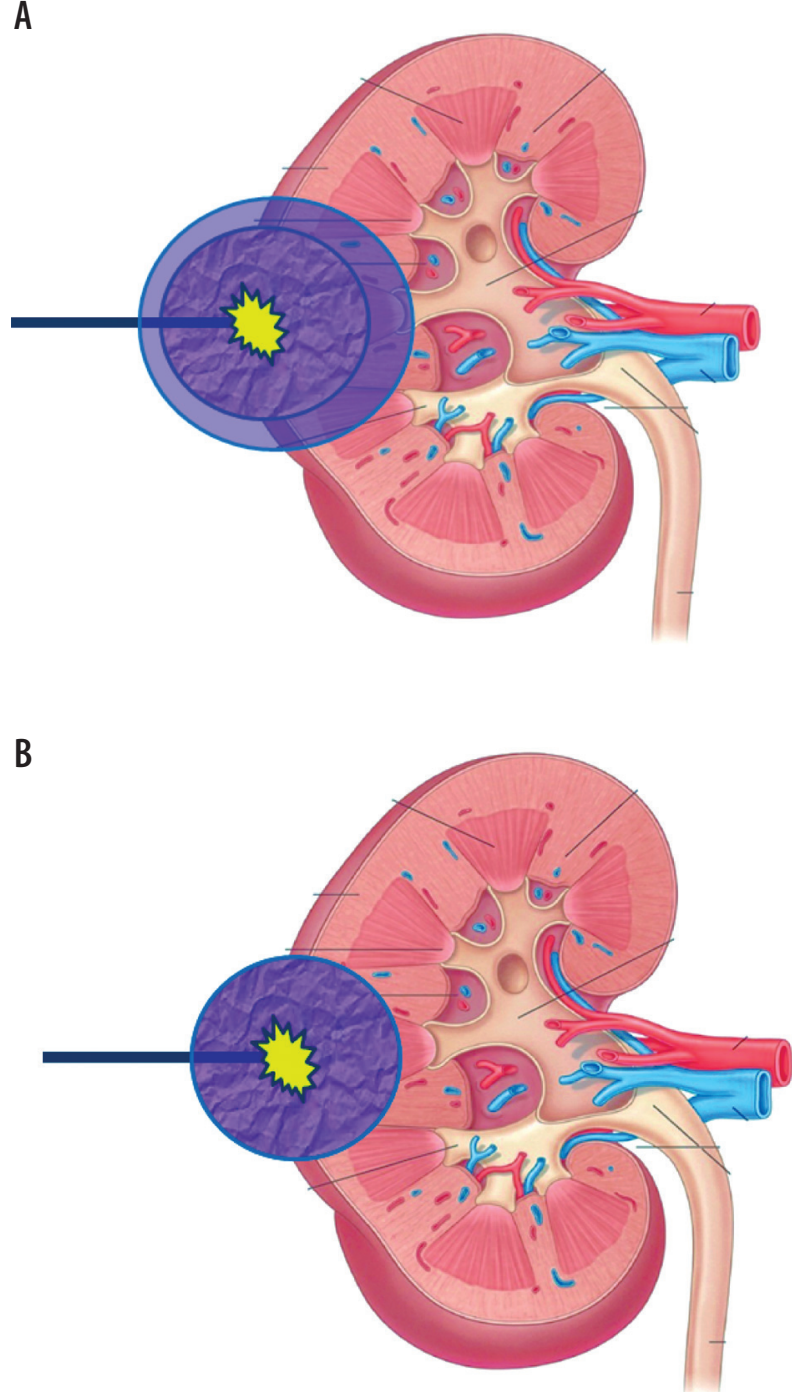

Figure 4. A) Renal tumour ablation with safety margin and damage to the peritumoral healthy parenchyma. B) Renal tumour ablation with no safety margin and no damage to the peritumoral healthy parenchyma ("ideal")

movement of the tumour and/or the organ necessitate the inclusion of a peritumoral safety margin of 5-10 $\mathrm{mm}$ in the healthy parenchyma (Figure 4A). More recent ablation methods, especially non-thermal ones, are aimed towards tumour ablation with a sharp demarcation of the tumour, without damage to the peritumoral parenchyma ("ablative ideal"; Figure 4B). The ablative measures are usually performed without ischaemia or embolisation. Thus, in respect of preservation of peritumoral parenchyma, the ablation is roughly comparable to renal tumour enucleoresection or enucleation, without relevant ischaemia time.

Radio-frequency ablation (RFA) and cryoablation (CA) are recommended in the guidelines of the German, European, and US-American societies for urology and radiology as alternative curative treatment options for small renal tumours in elderly patients with high morbidity, when operative or anaesthesiological risks or contra-indications are present [1-3]. Although these have been in 

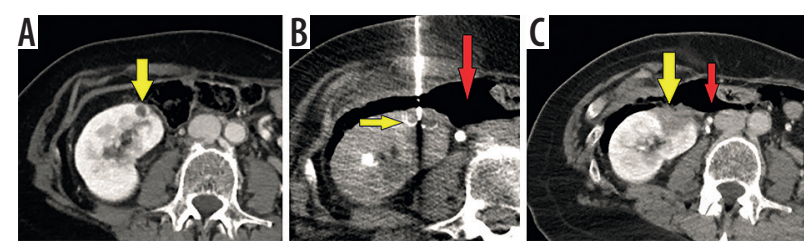

Figure 5. Radiofrequency ablation (RFA) of a renal cell carcinoma of the right kidney, A) pre-treatment (T scan of the right kidney with upper pole small renal mass (yellow arrow), B) CT scan of RFA probe (yellow arrow) with artificial pneumoperitoneum (red arrow) to displace the colon to avoid bowel necrosis/perforation, C) posttreatment (T scan immediately after RFA with complete necrosis of the ablation zone and tumour (yellow arrow) and the artificial pneumoperitoneum

use for some time, meaning a great deal of information is available, no results have been obtained in randomised, or even prospective, controlled studies. In a direct comparison of RFA with CA, neither procedure was found superior to the other in respect of survival (whether disease-related mortality, or progression-free or overall survival) [36]. Each has its own limitations on account of the thermoablative effect (heat-sink effect, cold-sink effect, thermal coagulative collateral damage). In the interests of more direct application and haemostasis, CA is preferentially used, by operative laparoscopy under general anaesthesia; consequently, it has no practical advantage over tumour resection, despite having the same risk of complications and being technically more complex than percutaneous RFA under local anaesthesia and analgosedation [36].

\section{Percutaneous radio-frequency thermoablation}

Percutaneous RFA is the interventional ablation method most frequently used as an alternative, non-surgical treatment of RCC. It is technically simple and relatively quick (the ablation takes 10-20 min) under fluoroscopy (CT or magnetic resonance imaging - MRI) with analgosedation. RFA is a hyperthermal ablation procedure: a high-frequency $(375-480 \mathrm{kHz})$ alternating potential is applied through suitably placed needle electrodes; the resulting ion current and Joule heating to $60-100^{\circ} \mathrm{C}$ leads to coagulation necrosis [36]. The electrodes used are mostly expandable electrodes with multi-array tip of various sizes. A $5-10 \mathrm{~mm}$ safety margin is recommended for ablation. The primary success rate of RFA in SRM is between $90 \%$ and $100 \%$, depending upon the tumour's size and position; for technical reasons, this rate is higher for corticoperipheral SRMs and those below $3 \mathrm{~cm}$ in size $[27,37-40]$. Various studies have reported local recurrence for pT1a-RCC between $2 \%$ and $12 \%$ in the first five years after RFA [38,41-45]. Moreover, RFA allows repetition, with a secondary success rate rising to nearly $100 \%$ [46]. Complications following renal RFA (0-19\% of cases) are mostly mild $[1,39,40,42,43,47]$. Overall, RFA yields results comparable to those of partial renal resection, although no randomised studies have yet been de- scribed $[1-3,43,48]$. When long-term results are known, the indication may well be expanded to include RFA for treating T1a RCC. However, there is a limitation for renal tumours located centrally, directly adjacent to the hilus and the pelvicalyceal system or to large blood vessels. The strong vascularisation of RCC frequently leads, on account of the heat-sink effect (see above), to incomplete ablation $[49,50]$. RFA is not recommended in the vicinity of the pelvicalyceal system or the ureter on account of the risk of perforation, fistulation, or stricture $[1,2,42]$. These restrictions on the indication can be circumvented by alternative, non-thermal ablation methods (Figure 5).

\section{Alternative percutaneous non-thermal ablation methods}

Up to now, alternative ablation techniques have been of a largely experimental nature and have not been recommended in guidelines [1-3]. In particular, non-thermal procedures might be able to avoid thermal collateral damage and thus lead to expansion of the range of indications for RCC ablation. However, irreversible electroporation at its present stage of development is technically highly demanding and also requires intubation anaesthesia with complete muscular relaxation; therefore, it does not offer any clear advantage [51-53]. Early results of ongoing studies suggest a high potential for transcutaneous brachytherapy in the afterloading procedure and for stereotactic percutaneous radiotherapy. In particular, these radiotherapeutic procedures allow treatment without the need for anaesthesia - even in cases of large and irregularly shaped renal tumours, while taking account of respiratory movements of the kidneys.

In high-dose-rate brachytherapy (HDRBT), the target tissue is exposed to very high doses of radiation (> $12 \mathrm{~Gy} / \mathrm{h}$ ) by temporarily inserted radiation sources (preferentially the bemitting nuclide iridium192). After positioning of the BT catheter by Seldinger's method and analgosedation, the radiation sources are introduced for some 20-90 minutes and then removed; this follows exact, individual, three-dimensional dose planning and calculation of the duration of exposure, taking into account the target tumour volume. The characteristic fall-off in radiation intensity means that undesired high exposure of the surrounding tissue and the neighbouring organs is avoided. Currently, BT of RCC is being investigated in two ongoing prospective phase I and phase II studies in the Department of Radiology and Nuclear Medicine at Magdeburg University Hospital in Germany [36]. Preliminary results suggest good controllability and a good response of the RCC. Analogously, a high local tumour control in HDRBT, using the same techniques, has been found for adrenal-gland malignomas [54] (Figure 6).

Modern stereotactic ablative radiotherapy ("stereotactic ablative body radiotherapy" - SABR) allows precise, focussed, hypofractionated irradiation ("radiosurgery", 24-40 Gy over one to five fractions in single doses of 
4-25 Gy each) in the cytotoxic region for RCC that is otherwise resistant to conventional radiotherapy. Siva et al. studied 223 patients treated with SABR (118 with single-fraction and 105 with multi-fraction treatments) and observed local control of $97.8 \%$ after four years, with only mild toxicity (grades 1 and 2, 35.6\%; grades 3 and 4 , $1.3 \%$ ) [55]. Siva et al. reported from 33 patients with $62 \%$ $\mathrm{T} 1 \mathrm{~b}, 35 \% \mathrm{~T} 1 \mathrm{a}$, and 3\% T2a RCC that freedom from local progression, distant progression, and overall survival rates at two years were $100 \%, 89 \%$, and $92 \%$, respectively. The mean baseline glomerular filtration rate was $55 \mathrm{ml} / \mathrm{min}$, which decreased to $44 \mathrm{ml} / \mathrm{min}$ at one and two years $(p<0.001)$ [56]. In the German guidelines this procedure is already mentioned as a potential future treatment option [1].

\section{Practical summary}

- For patients aged over 75 years, with small RCC $(<3-4 \mathrm{~cm})$, and with heightened comorbidity or advanced chronic renal insufficiency, an individual risk-benefit assessment should be performed between operative tumour resection on the one hand (as gold standard: enucleation, partial resection) and interventional ablation on the other (as an alternative treatment).

- Percutaneous biopsy, for histological confirmation and risk stratification, must be performed before ablation or AS.
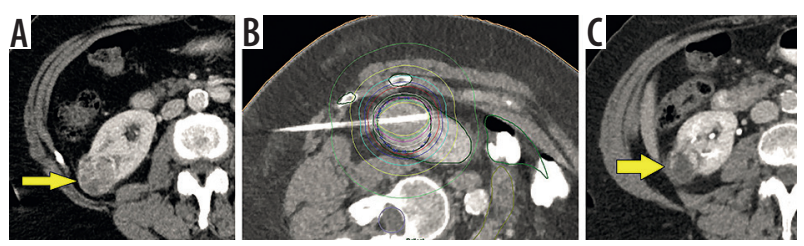

Figure 6. High-dose-rate brachytherapy (HDR-BT) of a renal cell carcinoma of the right kidney, A) pre-treatment (T scan of the right kidney with lower pole small renal mass (yellow arrow), B) CT scan of brachytherapy probe with treatment planning (isodose volume calculations) of high-dose-rate brachytherapy (afterloading), C) posttreatment (T scan 2 years after HDR-BT with involution of the tumour (yellow arrow)

- AS, a postponement of curative treatment with close imaging-based observation, is only to be recommended for selected patients with a low-risk RCC smaller than $3 \mathrm{~cm}$.

- As an alternative, guideline-based ablation procedure for treating SRM or RCC, percutaneous thermoablative RFA without general anaesthesia has the most advantages.

- Among the ablation methods hitherto regarded as experimental, HDBRT and SABR - both non-thermal radiotherapeutic procedures - at present show the greatest potential.

\section{Conflict of interest}

The authors report no conflict of interest.

\section{References}

1. Guideline program oncology (German Cancer Society, German Cancer Aid, AWMF): Diagnostic, therapy and follow-up of the renal cell carcinoma, long version 1.2, 2017, AWMF registry number: 043/017OL. Available from: http://leitlinienprogramm-onkologie. de/Nierenzellkarzinom.85.0.html. Accessed: 16 Aug 2018.

2. European Association of Urology (2018) EAU Guidelines. Edn. presented at the EAU Annual Congress Copenhagen 2018. ISBN 978-94-92671-01-1. Available from: http://uroweb.org/guideline/ renal-cell-carcinoma/. Accessed: 16 Aug 2018.

3. American Urological Association Education and Research (2017). Renal mass and localized renal cancer: AUA guideline. Available from: http://www.auanet.org/guidelines/renal-mass-and-localizedrenal-cancer-new-(2017). Accessed: 16 Aug 2018.

4. Brierley JD, Gospodarowicz MK, Wittekind C (eds.). TNM classification of malignant tumors. UICC International Union Against Cancer, 8th ed. Wiley-Blackwell, Hoboken 2017; 199.

5. Wittekind BJ, Compton CCC, Sobin LH (Hrsg). A commentary on uniform use. UICC International Union Against Cancer, 4th ed. Wiley-Blackwell, Hoboken 2013; 106.

6. Frank I, Blute ML, Cheville JC, et al. Solid renal tumors: an analysis of pathological features related to tumor size. J Urol 2003; 170: $2217-2220$
7. Wein A, Kavoussi L, Partin AW, Peters CA. Campbell-Walsh Urology. $11^{\text {th }}$ ed. Elsevier, Philadelphia 2016.

8. Ziegelmüller BK, Spek A, Szabados B, et al. Epidemiology and diagnostic assessment of small renal masses. Urologe 2018; 57: 274-279.

9. Chawla SN, Crispen PL, Hanlon AL, et al. The natural history of observed enhancing renal masses: metaanalysis and review of the world literature. J Urol 2006; 175: 425-431.

10. Jewett MA, Mattar K, Basiuk J, et al. Active surveillance of small renal masses: progression patterns of early stage kidney cancer. Eur Urol 2011; 60: 39-44.

11. Thompson RH, Hill JR, Babayev Y, et al. Metastatic renal cell carcinoma risk according to tumor size. J Urol 2009; 182: 41-45.

12. Kim M, Choi WS, Jeong CW, et al. Differences in peritumoral pseudocapsule characteristics according to clinicopathological factors in clinical T1a renal tumors. Int J Clin Exp Pathol 2013; 8: 1132311331.

13. Xi W, Wang J, Liu L, et al. Evaluation of tumor pseudocapsule status and its prognostic significance in renal cell carcinoma. J Urol 2018; 199: 915-920.

14. Raz O, Mendlovic S, Leibovici D, et al. The prevalence of malignancy in satellite renal lesions and its surgical implication during nephron sparing surgery. J Urol 2007; 178: 1892-1895. 
15. Volpe A, Finelli A, Gill IS, et al. Rationale for percutaneous biopsy and histologic characterisation of renal tumours. Eur Urol 2012; 62 : 491-504.

16. Mager R, Frees $S$, Haferkamp A. Watchful waiting and active surveillance of small renal masses. Urologe 2018; 57: 295-299.

17. Trpkov K, Yilmaz A, Uzer D, et al. Renal oncocytoma revisited: a clinicopathological study of 109 cases with emphasis on problematic diagnostic features. Histopathology 2010; 57: 893-906.

18. Wagener N. Renal cell carcinoma in older and geriatric patients. Urologe 2017; 56: 1019-1024.

19. Surbone A, Kagawa-Singer M, Terret C, et al. The illness trajectory of elderly cancer patients across cultures: SIOG position paper. Ann Oncol 2007; 18: 633-638.

20. Puts MT, Hardt J, Monette J, et al. Use of geriatric assessment for older adults in the oncology setting: a systematic review. J Natl Cancer Inst 2012; 104: 1133-1163.

21. Wedding U. Geriatric assessment in urology. In: Michel MS, Thüroff JW, Janetschek G, et al. The Urology. Springer, Heidelberg 2016; S2273-S2280.

22. Charlson ME, Pompei P, Ales KL, et al. A new method of classifying prognostic comorbidity in longitudinal studies: development and validation. J Chronic Dis 1987; 40: 373-383.

23. Panella L, Tinelli C, Buizza A, et al. Towards objective evaluation of balance in the elderly: validity and reliability of a measurement instrument applied to the Tinetti test. Int J Rehabil Res 2008; 31: 65-72.

24. Peyton CC, Heavner MG, Rague JT, et al. Does sarcopenia impact complications and overall survival in patients undergoing radical nephrectomy for stage III and IV kidney cancer? J Endourol 2016; 30: $229-236$

25. Abouassaly R, Yang S, Finelli A, et al. What is the best treatment strategy for incidentally detected small renal masses? A decision analysis. BJU Int 2011; 108: E223-E231.

26. Berger J, Fardoun T, Brassart E, et al. Detailed analysis of morbidity following nephrectomy for renal cell carcinoma in octogenarians. J Urol 2012; 188: 736-740.

27. Lane BR, Abouassaly R, Gao T, et al. Active treatment of localized renal tumors may not impact overall survival in patients aged 75 years or older. Cancer 2010; 116: 3119-3126.

28. Sun M, Bianchi M, Trinh QD, et al. Comparison of partial vs radical nephrectomy with regard to other-cause mortality in T1 renal cell carcinoma among patients aged $\geq 75$ years with multiple comorbidities. BJU Int 2013; 111: 67-73.

29. Sun M, Becker A, Tian Z, et al. Management of localized kidney cancer: calculating cancer-specific mortality and competing risks of death for surgery and nonsurgical management. Eur Urol 2014; 65: 235-241.

30. Haferkamp A. Diagnosis and treatment of small renal masses. Urologe 2018; 57: 272-273.

31. Hellenthal NJ, Mansour AM, Hayn MH, et al. Renal cell carcinoma in octogenarians: nephron sparing surgery should remain the standard of care. J Urol 2011; 185: 415-420.

32. Pierorazio PM, Johnson MH, Patel HD, et al. Management of renal masses and localized renal cancer: systematic reviewandmeta-analysis. J Urol 2016; 196: 989-999.
33. Schmit GD, Kurup AN, Weisbrod AJ, et al. ABLATE: a renal ablation planning algorithm. AJR Am J Roentgenol 2014; 202: 894-903.

34. Moskowitz D, Chang J, Ziogas A, et al. Treatment for T1a renal cancer substratified by size: "less is more". J Urol 2016; 196: 1000-1007.

35. Kriegmair MC, Wagener N, Diehl SJ, et al. Ablative therapy of small renal masses. Urologe 2018; 57: 285-294.

36. Wendler JJ, Friebe B, Baumunk D, et al. Focal therapy for small renal masses: Observation, ablation or surgery. Urologe 2016; 55: 594-606.

37. Clark TWI, Malkowicz B, Stavropoulos SW, et al. Radiofrequency ablation of small renal cell carcinomas using multitined expandable electrodes: preliminary experience. J Vasc Interv Radiol 2006; 17: 513-519.

38. Breen DJ, Rutherford EE, Stedman B, et al. Management of renal tumors by image-guided radiofrequency ablation: experience in 105 tumors. Cardiovasc Intervent Radiol 2007; 30: 936-942.

39. Ferakis N, Bouropoulos C, Granitsas T, et al. Long term results after computed tomography-guided percutaneous radiofrequency ablation for small renal tumors. J Endourol 2010; 24: 1909-1913.

40. Zagoria RJ, Pettus JA, Rogers M, et al. Long-termoutcomes after percutaneous radiofrequency ablation for renal cell carcinoma. Urology 2011; 77: 1393-1397.

41. Kunkle DA, Uzzo RG. Cryoablation or radiofrequency ablation of the small renal mass: a meta-analysis. Cancer 2008; 113: 2671-2680.

42. Wah T, Irving H, Gregory W, et al. Radiofrequency ablation (RFA) of renal cell carcinoma (RCC): experience in 200 tumours. BJU Int 2014; 113: 416-428.

43. Olweny EO, Park SK, Tan YK, et al. Radiofrequency ablation versus partial nephrectomy in patients with solitary clinical T1a renal cell carcinoma: comparable oncologic outcomes at a minimum of 5 years of follow-up. Eur Urol 2012; 61: 1156-1161.

44. Psutka SP, Feldman AS, McDougal WS, et al. Long-term oncologic outcomes after radiofrequency ablation for $\mathrm{T} 1$ renal cell carcinoma. Eur Urol 2013; 63: 486-492.

45. Kroeger N, Choueiri TK, Lee JL, et al. Survival outcome and treatment response of patients with late relapse from renal cell carcinoma in the era of targeted therapy. Eur Urol 2013; 65: 1086-1092.

46. Tracy CR, Raman JD, Donnally C, et al. Durable oncologic outcomes after radiofrequency ablation: experience from treating 243 small renal masses over 7.5 years. Cancer 2010; 116: 3135-3142.

47. Varkarakis IM, Allaf ME, Inagaki T, et al. Percutaneous radio frequency ablation of renal masses: results at a 2-year mean followup. J Urol 2005; 174: 456-460.

48. Takaki H, Yamakado K, Soga N, et al. Midterm results of radiofrequency ablation versus nephrectomy for T1a renal cell carcinoma. Jpn J Radiol 2010; 28: 460-468.

49. Rendon RA, Kachura JR, Sweet JM, et al. The uncertainty of radio frequency treatment of renal cell carcinoma: findings at immediate and delayed nephrectomy. J Urol 2002; 167: 1587-1592.

50. Klingler HC, Marberger M, Mauermann J, et al. "Skipping” is still a problem with radiofrequency ablation of small renal tumours. BJU Int 2007; 99: 998-1001.

51. Wendler JJ, Pech M, Fischbach F, et al. Initial assessment of the efficacy of irreversible electroporation in the focal treatment of localized renal cell carcinoma with delayed-interval kidney tumor resection (irreversible electroporation of kidney tumors before par- 
tial nephrectomy [IRENE] trial-an ablate-and-resect pilot study). Urology 2018; 114: 224-232.

52. Wendler JJ, Pech M, Köllermann J, et al. Upper-urinary-tract effects after IRreversible Electroporation (IRE) of human localised renal-cell carcinoma (RCC) in the IRENE pilot phase $2 \mathrm{a} a \mathrm{a}$ late-and-resect study. Cardiovasc Intervent Radiol 2018; 41: 466476.

53. Wendler JJ, Fischbach K, Ricke J, et al. Irreversible electroporation (IRE): standardization of terminology and reporting criteria for analysis and comparison. Pol J Radiol 2016; 81: 54-64.
54. Mohnike K, Neumann K, Hass P, et al. Radioablation of adrenal gland malignomas with interstitial high-dose-rate brachytherapy: efficacy and outcome. Strahlenther Onkol 2017; 193: 612-619.

55. Siva S, Louie AV, Warner A, et al. Pooled analysis of stereotactic ablative radiotherapy for primaryrenal cell carcinoma: A report from the International Radiosurgery OncologyConsortium for Kidney (IROCK). Cancer 2018; 124: 934-942.

56. Siva S, Pham D, Kron T, et al. Stereotactic ablative body radiotherapy for inoperable primary kidney cancer: a prospective clinical trial. BJU Int 2017; 120: 623-630. 